in Iran compared to the West. That may also enable Iran to buy up a number of Western scientists to tide them over the next few years.

International contacts are necessary not only for the placing of students oveaseas but also for the development of research programmes. Contacts are encouraged through sabbatical leave every fourth year and by financing international meetings in Iran. A recent example was the four-day meeting on the eukaryotic genome at the University of Tehran in May. About 40 Western experts were imported to expound on their research before an audience of about the same number of local scientists. No doubt the prestige of such an occasion is as important as the chance of making contacts; the actual symposium presentation probably come a poor third in real value.

Whereas Iran is presently looking determinedly to the West for international collaboration and advice, many Iranian scientists would like to develop a more regional approach. In particular that would make sense for programmes of "regional technology" in, for example, solar energy, desalination and arid zone research. Already there are programmes of cooperation with various Arab countries, Turkey and Pakistan. A bigger attraction for some would be Israel because of her scientific expertise both in basic research and in "regional technology". Although there is already a certain

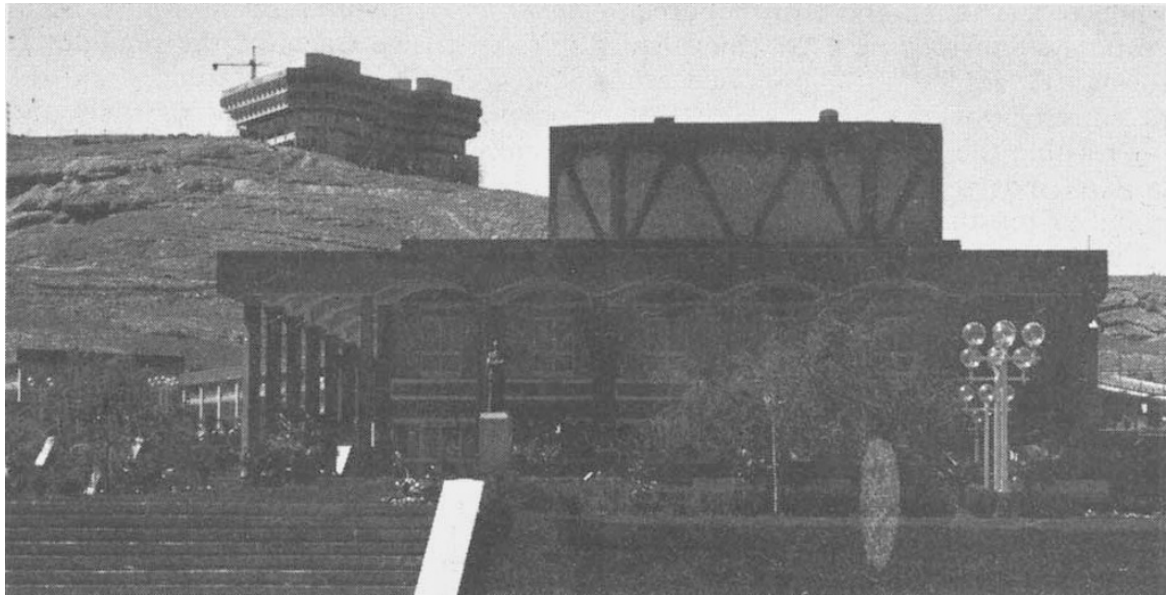

University of Shiraz, Iran

amount of informal contact with Israel, pclitical factors rule out any real cooperation.

There is in Iran an ancient tradition of science and technology. Its origins lie in the precise requirements of the Islamic faith for the time and direction of prayer. But tradition has nothing to offer to the new generation of Iranian scientists who are whole-heartedly committed to transplanting Western science, warts and all, to the Middle East. Whilst recognizing the need for a scientific discipline to have roots in the society that supports it, they argue that Iranian society is in the process of general change and in time will be ready to nourish the roots of Westernstyle science. The concurrent argument is that without generous support of basic research, no roots, in the form of Iranian eminence, will form.

The transplantation of Western values in science and much besides has, not surprisingly, led to certain problems in the universities as well as in Iranian society at large. In particular there are difficulties of adjustment for come from poorer, more traditional backgrounds. The result is a high dropout rate and sporadic political dissent which is ruthlessly suppressed. Overall, the Shah will not for the present tolerate any public questioning of his drive to make Iran a military and industrial force to be reckoned with. the growing number of students who

\title{
Conservation in Iran
}

\section{Peter D. Moore, recently in Iran, looks at attempts to conserve wildlife in a fast changing country}

$\mathbf{N}^{A}$ ATURE conservation in the industrialised nations is said to be a cause associated primarily with the middle classes. Developing countries often see it as a worthwhile economic exercise, since wildlife parks can be a major tourist attraction providing foreign currency. But in Iran it is neither of these. There is little tourist industry apart from that which centres upon the archaeological rather than wildlife potential of the country. Yet conservation ranks high among the priorities of the government. The Iranian Department of the Environment, headed by Eskandar Firouz, is (unlike the British establishment of the same name) primarily concerned with environmental research and practical management problems in Iran's cities, rural areas, wildlife parks and reserves, and around its Persian Gulf and Caspian Sea coasts.

The sheer size of the country (about three times the area of France) and its altitudinal variation (from $50 \mathrm{~m}$ below sea level at the Caspian to $5,700 \mathrm{~m}$ in the Elburz mountains near Tehran) results in a wide range of habitats and a high diversity of wildlife. About $80 \%$ of Iran is over $1000 \mathrm{~m}$ in altitude: much of this lies in a great central plateau surrounded by high mountains, the physical isolation of which could account for the high proportion of endemics in the Iranian flora.

To ensure that examples of all the major habitats are conserved, the Environment Department has established over 40 wildlife parks and protected areas, covering a combined area larger than Switzerland. The broad-leaved forests of the Caspian area still contain wild pig, brown bear and the Persian subspecies of fallow deer, which has been rescued from the verge of extinction. Tigers were reported from this region in the first half of the century, but are now feared extinct.
The Caspian lowlands also contain some important wetland areas which serve as winter feeding grounds for large populations of wildfowl that breed in western Siberia. Other wetland areas in Iran are mainly in the west, especially the saline lakes: the largest is Lake Rezaiyeh, which extends over 3,000 ha and supports breeding populations of 25,000 pairs of greater flamingo and 1,400 pairs of white pelican. The wetlands of the Gulf in the south of Iran include the Eastern Mesopotamian marshes and the rivers of Iranian Baluchistan, where the marsh crocodile still survives at the western limit of its range.

The wealth of wetland habitats which Iran contains, coupled with the threat which is posed to them by increasing industrialisation, may explain why Iran has become a global trend-setter in the field of wetland conservation. In February 1971, a Convention was agreed at an international conference in Ramsar, Iran, by which all signatory member countries should designate at least one of their wetland sites for inclusion in a list of wetlands of international importance. Iran was the second country to ratify this treaty, 
while it has taken the British bureaucratic system five years to achieve this formality, despite the lip-service paid to conservation.

Probably the greatest threat to Iranian wetlands is posed by the industrial pollution of the Caspian Sea and the oil pollution of the Persian Gulf. In the Caspian much of the polfution is derived from the Soviet Union, but there is now cooperation between the two countries in trying to reduce its level. Worst affected is the fishing industry, where the production of sturgeon and caviar provides an important export industry. Attempts to reduce pollution are being coupled with the building of fish breeding stations. Near Rasht on the Sefid river, which runs into the Caspian, one such site of 132 ha has been built with Soviet aid and at a cost of $\$ 5$ million. It produces 4 million fish per year which are released into the river.

At the other end of the habitat spectrum, almost half of the surface area of Iran is covered by desert or arid steppe, and obviously this type of habitat is well represented among its reserves. Here, in particular, human exploitation or the environment and wildlife conservation reaches a delicate and precarious balance. A relatively small percentage of Iran's population is involved in pastoralism and these people are found mainly in the semiarid areas. Precise and accurate figures are difficult to obtain, but it has been estimated that about 400,000 pastoralists maintain a total of 30 million sheep and 15 million goats, so the grazing pressure over the arid lands is extremely high. These herds reduce the wildlife potential of the areas they graze, but it is difficult to establish whether this is a result of their consumption of herbage or simply the disturbance caused by a human presence.

The arid areas contain a rich and varied assortment of wildlife, now much depleted through hunting. Wild ass, goitered and jebeer gazelle, cheetah, leopard, wild sheep, great and houbara bustards, all still survive in viable populations within the protected regions. The large raptorial birds, particularly the golden eagle, are surprisingly frequent given that such species have often suffered at the hands of pastoralists. The maintenance of this wildlife must depend, however, upon restricting any further human pressures upon their dwindling populations, and this raises a number of social and political problems.

Before any such problems can be solved, it must be ascertained precisely what form man's interaction with wildlife takes. Studies of the productivity of the natural flora are needed urgently, particularly in the Zygo-
phyllum/Artemisia scrub which occupies extensive tracts of the semi-desert areas. The feeding preferences and the potential consumption of the wild and domestic herbivores must also be known, so that competitive interactions can be identified and the carrying capacity of the environment for each species determined. Also, in spite of Iran's wealth of fossil fuel deposits, there is an acute shortage of fuel in the settlements of the desert area and much shrub material is gathered for combustion. A knowledge of the social practices of the people is therefore needed, including an understanding of the movements of the small groups of pastoralists who indulge in transhumance, leaving the desert plateau for the mountain pastures each spring. The historical and archaeological perspective is also important, for some desert areas have been denuded of scrub, and perhaps even of pistachio woodland, for charcoal burning and smelting in the past. It is possible that the great salt lakes or kavirs will contain preserved, stratified pollen from which past changes in vegetation can be determined.

An integrated study of these various aspects of the desert ecosystem is currently being undertaken by the Department of the Environment's Bureau of Arid Lands Ecology in the Turan Protected Area of eastern Iran. The solution to another environmental problem, dune stabilisation, is also the subject of an experimental approach. Some 5 million hectares of sand dunes, mainly in south-eastern Iran, provide a very unstable substrate which results in low plant cover and productivity. Since 1968, Esso Research I td has been spraying dunes with oil to provide a temporary stabilization of surface sand whilst plant life is becoming established. Oil is deposited at a density of about 4 tons per hectare, and the area is then planted with fastgrowing shrubs, some of which may attain a height of 2 metres within 2 years and seem unaffected by the oil deposits around their roots. Although the initial effect is unsightly, the final stabilisation is said to be more effective than that achieved by the old system of using brushwood palisades and, in a country where oil is cheap, the method may provide a fast and efficient method of dune reclamation, whether for human or wildlife exploitation.

Plans are meanwhile being put into operation to develop an environmental park, called "Pardisan", within the city of Tehran. A 300 ha site will eventually contain museums, planetarium, aquarium, laboratory complex and a series of reconstructions of various habitats, including fauna, from Iran and other parts of the world. As with the Environment Department's other conservation activities, emphasis is to be placed upon the role of man in the ecosystems portrayed, so the zoological/ botanical garden is to be combined with a kind of folk museum in which whole villages will be constructed typical of such areas as the Persian Gulf and Baluchistan. This grand conception, the brainchild of Firouz, has much about it which is attractive, but its practical feasibility remains to be demonstrated.

The one pervasive feature of the Iranian approach to wildlife and habitat conservation is its insistence upon the inclusion of man as a component of all its ecosystems. This country, with about 10,000 years of agricultural history, bears everywhere the mark of man's activities. There are regions which almost certainly could be made more productive if man were to reduce his demand on the environment, but no realistic conservation policy can ignore or totally exclude his presence. It is to be hoped that such enlightened attitudes will penetrate to all levels of Iranian society and will result in the achievement of a balance from which all organisms, including man, will ultimately benefit.

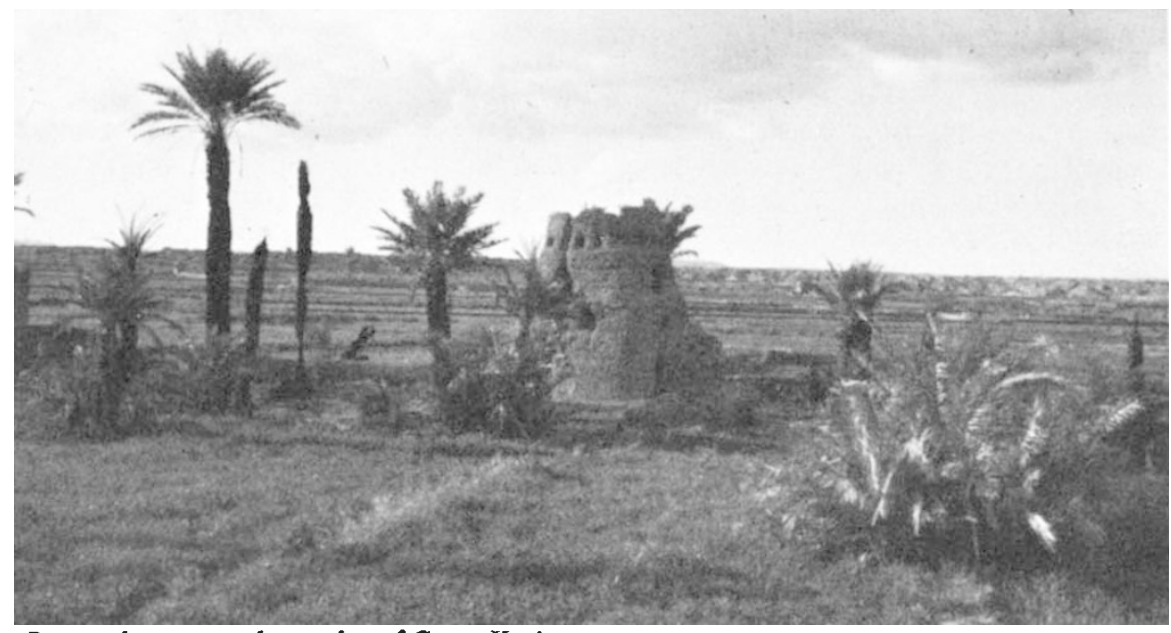

